\title{
PENGARUH KANDUNGAN KIMIA AIR TERHADAP KUAT TEKAN BETON
}

\author{
R. Dedi Iman Kurnia ${ }^{\text {() }}$, Syarizal Fonna ${ }^{2)}$, Syifaul Huzni ${ }^{3)}$, Suhaimi ${ }^{4)}$ \\ 1), 4) Program Studi Teknik Sipil Fakultas Teknik Universitas Almuslim \\ ${ }^{2), 3)}$ Program Studi Teknik Mesin Fakultas Teknik Universitas Syiah Kuala \\ Email: adenrestoration@gmail.com ${ }^{1)}$, syarizal.fonna@unsyiah.ac.id ${ }^{2}$, \\ syifaul@unsyiah.ac.id ${ }^{3}$, suhaimi_civil@yahoo.com ${ }^{4)}$
}

DOI: $\underline{\text { http://dx.doi.org/10.29103/tj.v10i1.260 }}$

(Received: November 2019 / Revised: February 2020 / Accepted: Maret 2020)

\begin{abstract}
Abstrak
Sebagian besar masyarakat di wilayah Kabupaten Bireuen menggunakan sumber air alami yang tersedia di sekitar lokasi pekerjaan sebagai air campuran beton tanpa mengetahui kualitas air yang digunakan. Kondisi seperti ini dikhawatirkan dapat mempengaruhi kualitas dan karakteristik beton yang dihasilkan. Penelitian dilakukan dengan tujuan untuk mengetahui kualitas dan kandungan kimia air tanah yang digunakan sebagai air campuran beton serta pengaruhnya terhadap kuat tekan beton yang dihasilkan. Air tanah yang digunakan sebagai air campuran bersumber dari 3 (tiga) lokasi dalam kawasan Kabupaten Bireuen, yaitu Gampong Paya (AT I), Gampong Teupok Teungoh (AT II) dan Gampong Pulo Lawang (AT III) serta air suling (AS) sebagai pembanding. Benda uji yang digunakan berbentuk silinder dengan nilai FAS campuran 0,52. Pengujian kuat tekan dilakukan pada umur beton 7, 14, 28 dan 56 hari. Dari hasil penelitian diketahui bahwa klorida dan sodium merupakan unsur kimia yang paling dominan terkandung dalam air tanah selain sulfat dan komponen unsur kimia lainya. Kuat tekan beton yang menggunakan air tanah sebagai air campurannya memiliki nilai kuat tekan akhir yang lebih kecil dibandingkan beton yang menggunakan air suling. Kandungan klorida dan sodium dengan jumlah yang dominan dalam air tanah (sebagai air campuran) menyebabkan kuat tekan beton meningkat pada awal umur pengujian (7 dan 14 hari), tetapi mengalami penurunan secara signifikan pada umur pengujian 28 dan 56 hari. Berdasarkan ASTM C 1602 M04 dan hasil pengujian kuat tekan beton disimpulkan bahwa sampel air AT III layak digunakan sebagai air campuran beton, sedangkan sampel air AT I dan AT II tidak layak digunakan sebagai air campuran beton.
\end{abstract}

Kata Kunci: Kuat tekan beton, air campuran beton, kandungan kimia air tanah, air suling,

\begin{abstract}
Most people in the Bireuen district use natural water sources that are available around the work site as concrete mixed water without knowing the quality of the water used. This condition is feared to affect the quality and characteristics of the concrete produced. The study was conducted with the aim to determine the quality and chemical content of ground water used as concrete mix water and its effect on the compressive strength of the concrete produced. Ground water used as mixed water is sourced from 3 (three) locations in the Bireuen Regency area, namely Paya Village (AT I), Teupok Teungoh Village (AT II) and Pulo Lawang Village (AT III) and distilled water (AS) as a comparison. The specimen used was cylindrical with a mixed FAS value of 0.52. Compressive strength testing is performed at the age of 7, 14, 28 and 56 day. The results study note that chloride and sodium are the most dominant chemical elements contained in ground water in addition to sulfates and other chemical components. The compressive strength of concrete that uses ground water as
\end{abstract}


mixed water has a lower final compressive strength than concrete that uses distilled water. The dominant amount of chloride and sodium in ground water (as mixed water) influence the compressive strength of concrete to increase at the beginning of the test day (7 and 14 day), but decreased significantly at the age of testing 28 and 56 day. Based on ASTM C 1602 M-04 and the results of the concrete compressive strength test it was concluded that the AT III water sample was suitable for use as a concrete mix water, whereas the AT I and AT II water samples are not suitable for use as mixed concrete water.

Keywords: Concrete compressive strength, concrete mix water, groundwater chemical content, distilled water,

\section{Latar Belakang}

Perencananaan dan pelaksanaan pekerjaan konstruksi beton bertulang menjadi sangat penting mengingat banyak daerah di Indonesia yang masuk ke dalam wilayah rawan gempa. Keruntuhan bangunan secara tiba-tiba bisa saja terjadi karena pengaruh kondisi beban bangunan dan kombinasi beban gempa. Secara umum kerusakan bangunan terjadi karena durabilitas bangunan yang telah mengalami penurunan dari kondisi awalnya, dapat juga terjadi pada konstruksi yang baru dibangun akantetapi menggunakan kualitas material dan mutu pelaksanaan yang buruk (Tjokrodimuljo. K, 2007).

Sebagian besar wilayah Kabupaten Bireuen merupakan daerah pesisir. Masyarakat dan pelaksanaan konstruksi seringkali memanfaatkan sumber air alami yang tersedia di sekitar lokasi pekerjaan tanpa mengetahui kualitas air yang digunakan. Kecendrungan seperti ini terjadi dengan berbagai alasan dan kondisi penyebab. Secara umum dapat dikatakan kurangnya pengetahuan terhadap syarat mutu air sebagai bahan campuran beton. Kondisi air tanah di kawasan pesisir biasanya dipengaruhi oleh intrusi air laut, hal ini menyebabakan air tanah akan bersifat payau (R.D.I. Kurnia, dkk, 2018).

Beberapa penelitian mengemukakan bahwa klorida $(\mathrm{Cl})$, sulfat $\left(\mathrm{SO}_{4}\right)$ dan sodium (Na) dapat bereaksi dengan unsur - unsur yang terkandung dalam matrik semen dan dapat mempengaruhi proses hidrasi dan setting time (Khan. $\mathrm{H}$, dkk, 2016). Fenomena ini terjadi apabila unsur kimia tersebut terkandung dalam air campuran beton. Jika beton terpapar atau bahkan terendam dalam lingkungan yang ekstrim dengan kandungan garam tersebut maka efek degradasi yang ditimbulkan akan semakin cepat dan signifikan (Luca Bertolini, dkk, 2004). Pengaruh degradasi beton yang disebabkan serangan kimia menimbulkan efek dalam jangka panjang. Hal ini terjadi karena sebagian besar akibat yang ditimbulkan berupa pelapukan (Saribas. I, dkk, 2017).

Air payau umumnya mengandung senyawa garam dengan unsur utama berupa ion klorida $(\mathrm{Cl})$, sulfat $\left(\mathrm{SO}_{4}\right)$ dan sodium $(\mathrm{Na})$. Kualitas air dengan kandungan garam berlebih tidak baik dan tidak sesuai dengan persyaratan serta ketentuan air sebagai bahan pembentuk beton. Kondisi ini dapat mempengaruhi kualitas dan karakteristik beton yang dihasilkan. Kandungan unsur kimia dalam air tanah bervariasi, sehingga pengaruh yang timbul akan bervariasi pula (Khan. $\mathrm{H}$, dkk, 2016).

Perlu kiranya dilakukan penelitian berkaitan dengan kualitas dan kandungan kimia sumber air tanah terhadap kuat tekan beton yang dihasilkan, mengingat kurangnya referensi berkaitan dengan penelitian ini khususnya dalam lingkup 
Kabupaten Bireuen. Penelitian ini dilakukan untuk melihat kelayakan penggunaan air tanah sebagai air campuran beton dari beberapa lokasi dalam lingkup Kabupaten Bireuen.

\section{Metode Penelitian}

\subsection{Bahan}

Bahan-bahan yang akan digunakan sehubungan dengan penelitian adalah sebagai berikut:

1. Semen: Semen Portland tipe I PT. Semen Andalas Indonesia

2. Agregat halus (pasir): Ukuran butiran maksimum sebesar $4.5 \mathrm{~mm}$, bersumber dari Desa Teupin Mane Kecamatan Juli Kabupaten Bireuen.

3. Agregat kasar (kerikil): Ukuran butiran maksimum sebesar $31,5 \mathrm{~mm}$, bersumber dari Desa Pante Karya Kecamatan Peusangan Selatan Kabupaten Bireuen.

4. Air: Air tanah yang digunakan air campuran beton bersumber dari 3 (tiga) desa dalam kawasan Kabupaten Bireuen, yaitu Gampong Paya, Gampong Teupok Teungoh, Gampong Pulo Lawang dan air suling sebagai pembanding.

\subsection{Pemeriksaan Material}

Pemeriksaan sifat fisis material dilaksanakan di Laboratorium Teknologi Bahan Bangunan Teknik Sipil Universitas Almuslim. Pemeriksaan kandungan komposisi kimia air tanah dan air suling dilakukan di Laboratorium Penguji BARISTAND Banda Aceh (LABBA). Berikut ini adalah standar yang digunakan untuk pemeriksaan sifat fisis agregat dan kandungan kimia air tanah.

Tabel 1 Metode uji sifat fisis agregat dan kandungan komposisi kimia air tanah

\begin{tabular}{cll}
\hline No. & \multicolumn{1}{c}{ Parameter uji } & \multicolumn{1}{c}{ Metode pengujian } \\
\hline 1 & Analisis saringan agregat & ASTM C 136-06 \\
\hline 2 & Berat jenis dan penyerapan agregat & ASTMC-128 \& ASTMC-127 \\
\hline 3 & Kadar air agregat & ASTM C 566-97 \\
\hline 4 & Berat volume agregat & ASTM C-29 \\
\hline 5 & Klorida $\left(\mathrm{Cl}^{-}\right)$ & Tritrimeter $(\mathrm{SNI}$ 6439. 2013) \\
\hline 6 & Sulfat $\left(\mathrm{SO}_{4}\right)$ & Spektrofotometer \\
\hline 7 & Sodium $(\mathrm{Na})$ & Atomic absorption spectroscopy $(A A S)$ \\
\hline
\end{tabular}

\subsection{Rancangan campuran dan benda uji}

Perencanaan proporsi campuran dilakukan untuk memperoleh jumlah agregat, semen dan air. Dalam penelitian ini perencanaan proporsi campuran dilakukan berdasarkan metode ACI (American Concrete Institute). Faktor Air Semen (FAS) yang direncanakan adalah 0,52.

Tabel 2 Rancangan proporsi campuran beton (Mix Design)

\begin{tabular}{clccc}
\hline \multirow{2}{*}{ No. } & \multirow{2}{*}{ Material } & \multicolumn{2}{c}{ Komposisi campuran } & \multirow{2}{*}{ Satuan } \\
\cline { 3 - 4 } 1 & Air & 186,76 & $0.0053 \mathrm{~m}^{3}$ & \\
\hline 2 & Semen & 358,26 & 1,90 & $\mathrm{Kg}$ \\
\hline 3 & Agregat Kasar (Kerikil) & 1017,82 & 5,39 & $\mathrm{Kg}$ \\
\hline 4 & Agregat Halus (Pasir) & 832,76 & 4,41 & $\mathrm{Kg}$ \\
\hline
\end{tabular}


Benda uji yang digunakan berbentuk silinder dengan diameter $15 \mathrm{~cm}$ dan tinggi $30 \mathrm{~cm}$ sesuai standar ASTM C 39. Dua puluh (20) buah benda uji dibuat untuk setiap variasi air campuran, dengan total jumlah benda uji yang digunakan sebanyak 100 buah. Perawatan beton dilakukan dengan merendam benda uji sesuai dengan umur pengujian dalam dalam air suling. Pengujian kuat tekan dilakukan pada saat benda uji berumur 7, 14, 28 dan 56 hari.

\section{Hasil dan Pembahasan}

Menurut ASTM C 1602 M-04, ambang batas kandungan bahan kimia yang diizinkan untuk air yang digunakan sebagai air campuran beton, adalah sebagai berikut:

Tabel 3 Standard specification for mixing water used in the production of hydraulic cement concrete

\begin{tabular}{rlcr}
\hline NO & \multicolumn{1}{c}{$\begin{array}{c}\text { Max concentration in combined } \\
\text { water }\end{array}$} & Limits (ppm) & $\begin{array}{c}\text { Test } \\
\text { Methods }\end{array}$ \\
\hline 1 & Chloride as $\mathrm{Cl}^{-}$ & 500 & $\mathrm{C} 114$ \\
\hline 2 & Sulfate as $\mathrm{SO}_{4}$ & 3000 & $\mathrm{C} 115$ \\
\hline 3 & Alkalies as $\left(\mathrm{Na}_{2} \mathrm{O}+\mathrm{K}_{2} \mathrm{O}\right)$ & 600 & $\mathrm{C} 116$ \\
\hline
\end{tabular}

Tabel 4 Hasil pemeriksaan komposisi kandungan kimia sampel air

\begin{tabular}{lllccc}
\hline & & \multicolumn{2}{c}{ Kode } \\
\cline { 5 - 6 } No & $\begin{array}{c}\text { Sumber Sampel Air } \\
\text { Tanah }\end{array}$ & $\begin{array}{c}\text { Sampel } \\
\text { Air Tanah }\end{array}$ & $\begin{array}{c}\text { Klorida(Cl) } \\
(\mathrm{ppm})\end{array}$ & $\begin{array}{c}\text { Sodium }(\mathrm{Na}) \\
(\mathrm{ppm})\end{array}$ & $\begin{array}{c}\text { Sulfat(SO } \\
(\mathrm{ppm})\end{array}$ \\
\hline 1 & Air Suling & AS & 27,40 & 45,37 & 32,29 \\
\hline 2 & Gampong Paya & AT I & $2.959,72$ & 539,50 & 360,00 \\
\hline 3 & $\begin{array}{l}\text { Gampong Teupok } \\
\text { Teungoh }\end{array}$ & AT II & $1.589,93$ & 381,60 & 300,00 \\
\hline 4 & Gampong Pulo Lawang & AT III & 87,08 & 107,60 & 280,00 \\
\hline
\end{tabular}

Berdasarkan hasil pemeriksaan komposisi kandungan kimia air campuran pada Tabel 2 diketahui bahwa sampel air tanah dari Gampong Paya (AT I) dan Gampong Teupok Teungoh (AT II) memiliki kandungan klorida dengan jumlah yang sangat besar, hal yang sama juga terjadi pada kandungan sodiumnya. Apabila dihubungkan dengan Standard specification for mixing water ASTM C 1602 M-04 (Tabel 1), kandungan klorida untuk kedua sampel air tanah ini jauh di atas ambang batas yang diizinkan. Kandungan sodium pada kedua sampel air tanah ini masih dalam batas toleransi, namun demikian nilai kandungan sodium yang ada sudah mendekati ambang batas yang diizinkan. Sedangkan kandungan sulfat dari kedua sampel air tanah berada jauh di bawah ambang batas yang diizinkan. Hasil yang bertolak belakang terlihat pada pemeriksaan komposisi kandungan kimia sampel air suling (AS) dan air tanah dari Gampong Pulo Lawang (AT III) di mana kandungan klorida, sodium dan sulfat berada jauh dibawah ambang batas yang diizinkan. 
Khan. H, dkk (2016) menyatakan bahwa dalam air laut terdapat kandungan klorida dan sodium dengan persentase jumlah yang paling dominan, hal senada juga dikemukakan dalam buku yang ditulis oleh Saribas. I, dkk (2017). Dari Tabel 4 diketahui bahwa kandungan kimia sampel air tanah AT I dan AT II memiliki kemiripan dengan kandungan kimia air laut, di mana ditemukan kandungan klorida dan sodium dengan persentase jumlah yang paling dominan. Hal lain yang juga ditemukan dari hasil pemeriksaan komposisi kandungan kimia air (Tabel 3) adalah bahwa jumlah kandungan klorida dan sodium dalam air tanah berbanding terbalik dengan kandungan sulfat, jika kandungan klorida dan sodium tinggi maka kandungan sulfat akan rendah, begitu pula sebaliknya. Namun demikian hasil pemeriksaan komposisi kandungan kimia pada air suling (AS) menunjukkan fakta yang berbeda, di mana komposisi unsur kimia yang terkadung didalamnya tidak dapat dihubungkan secara spesifik antara satu dan lainnya.

Tabel 5 Hasil pengujian kuat tekan beton terhadap umur pengujian

\begin{tabular}{|c|c|c|c|c|c|c|}
\hline \multirow{3}{*}{ No } & \multirow{3}{*}{$\begin{array}{c}\text { Sumber Air Campuran } \\
\text { Beton }\end{array}$} & \multirow{3}{*}{$\begin{array}{c}\text { Kode } \\
\text { Benda } \\
\text { Uji }\end{array}$} & \multicolumn{4}{|c|}{ Nilai Kuat Tekan } \\
\hline & & & \multicolumn{4}{|c|}{$\operatorname{Mpa}\left(\mathrm{N} / \mathrm{mm}^{2}\right)$} \\
\hline & & & 7 Hari & 14 Hari & 28 Hari & 56 Hari \\
\hline 1 & Air Suling (adjustment) & BAS & 14,16 & 17,45 & 20,95 & 23,07 \\
\hline 2 & Gampong Paya & BAT I & 15,59 & 19,52 & 20,37 & 19,10 \\
\hline 3 & Gampok Teupok Teungoh & BAT II & 14,55 & 18,37 & 19,76 & 19,67 \\
\hline 4 & Gampong Pulo Lawang & BAT III & 13,86 & 17,21 & 20,71 & 21,65 \\
\hline
\end{tabular}

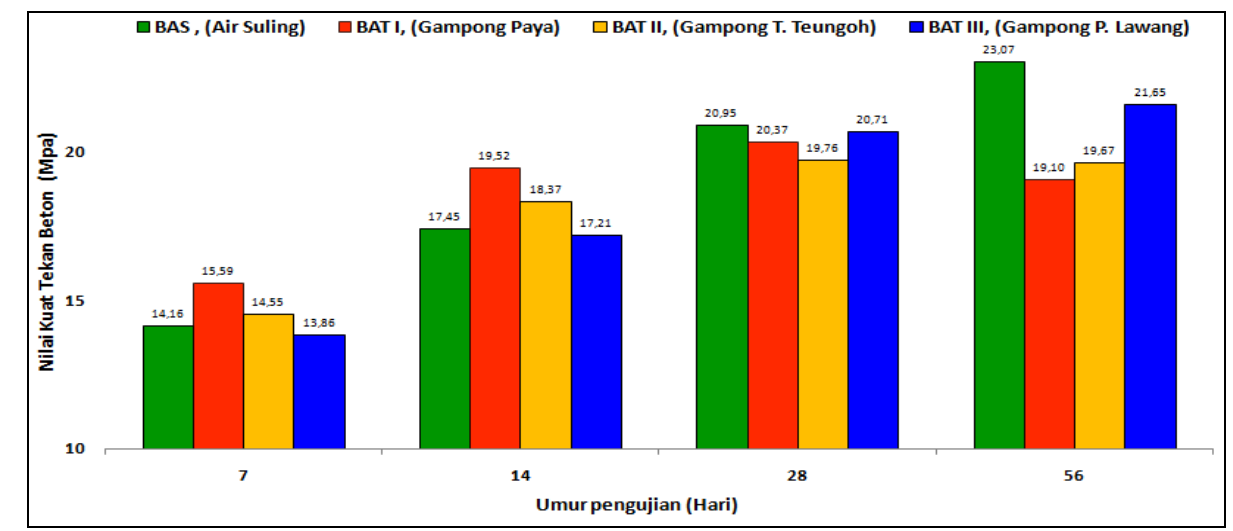

Gambar 1 Grafik hubungan nilai kuat tekan beton terhadap umur pengujian

Dari Tabel 3 dan Gambar 1 diketahui bahwa benda uji yang memiliki nilai kuat tekan paling tinggi hingga yang paling rendah pada umur pengujian 7 dan 14 hari berturut turut adalah BAT I, BAT II, BAS, dan BAT III. Namun pada umur pengujian 28 dan 56 hari terjadi perubahan pada perolehan nilai kuat tekan, dimana benda uji yang memiliki nilai kuat tekan paling tinggi hingga yang paling rendah berturut turut adalah BAS, BAT III, BAT II dan BAT I.

Gambar 2 secara spesifik memperlihatkan perbandingan nilai kuat tekan benda uji yang dibuat menggunakan air tanah (BAT I dan BAT II) dan air suling (BAS) sebagai pembanding. Berdasarkan Gambar 2 diketahui bahwa pada umur 7 dan 14 hari nilai kuat tekan benda uji BAS lebih kecil dari nilai kuat tekan benda 
uji BAT I dan BAT II. Pada saat benda uji berumur 28 dan 56 hari nilai kuat tekan benda uji BAS berbalik menjadi lebih besar dari nilai kuat tekan benda uji BAT I dan BAT II.

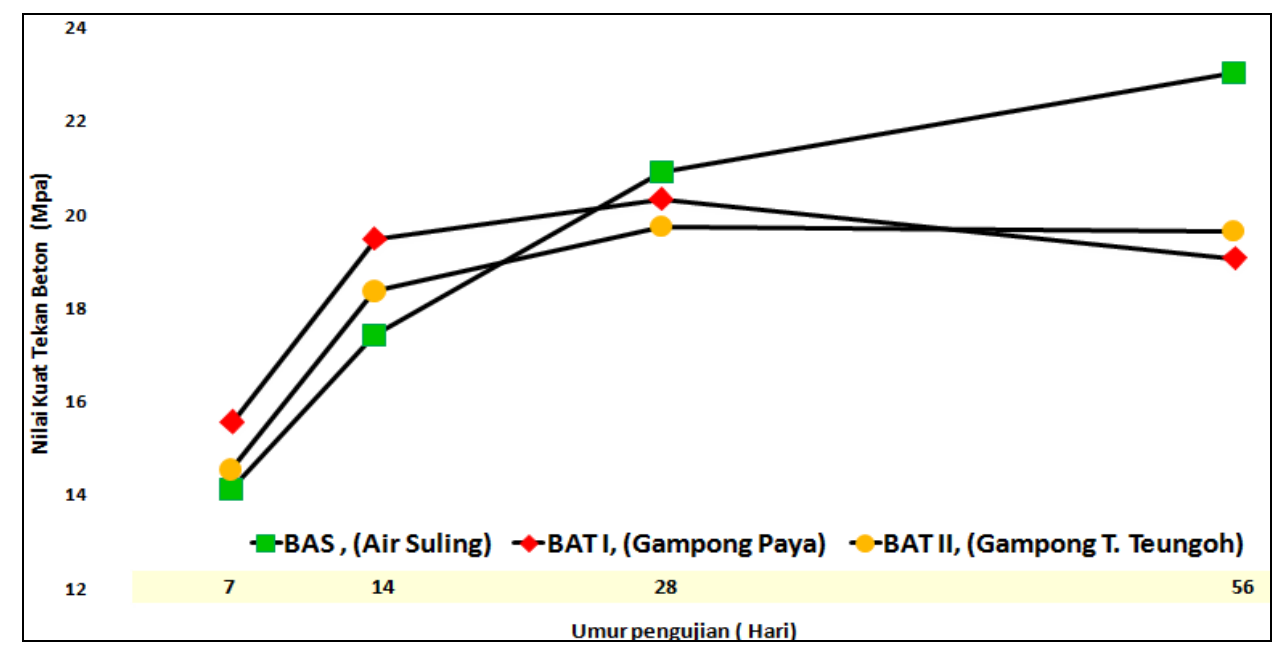

Gambar 2 Grafik hubungan nilai kuat tekan BAS, BAT I dan BAT II VS umur pengujian

Adanya perbedaan air yang digunakan sebagai air campuran beton terbukti berpengaruh terhadap nilai kuat tekan beton yang dihasilkan. Bila dihubungkan hasil pengujian kuat tekan beton pada Gambar 2 dengan hasil pemeriksaan komposisi kandungan kimia sampel air (Tabel 2), maka dapat dibuktikan bahwa jumlah kandungan klorida dan sodium dengan jumlah yang sangat dominan dalam air tanah (BAT I dan BAT II) menjadi penyebab terjadinya fenomena ini. Hasil penelitian yang serupa juga ditunjukkan dalam penelitian yang dilakukan oleh Khan. H, dkk (2016), di mana kandungan klorida dan sodium dalam air yang digunakan sebagai air campuran berpengaruh meningkatkan kuat tekan beton pada umur 7 hari, namun mulai memperlihatkan penurunan pada umur pengujian 28 dan 56 hari.

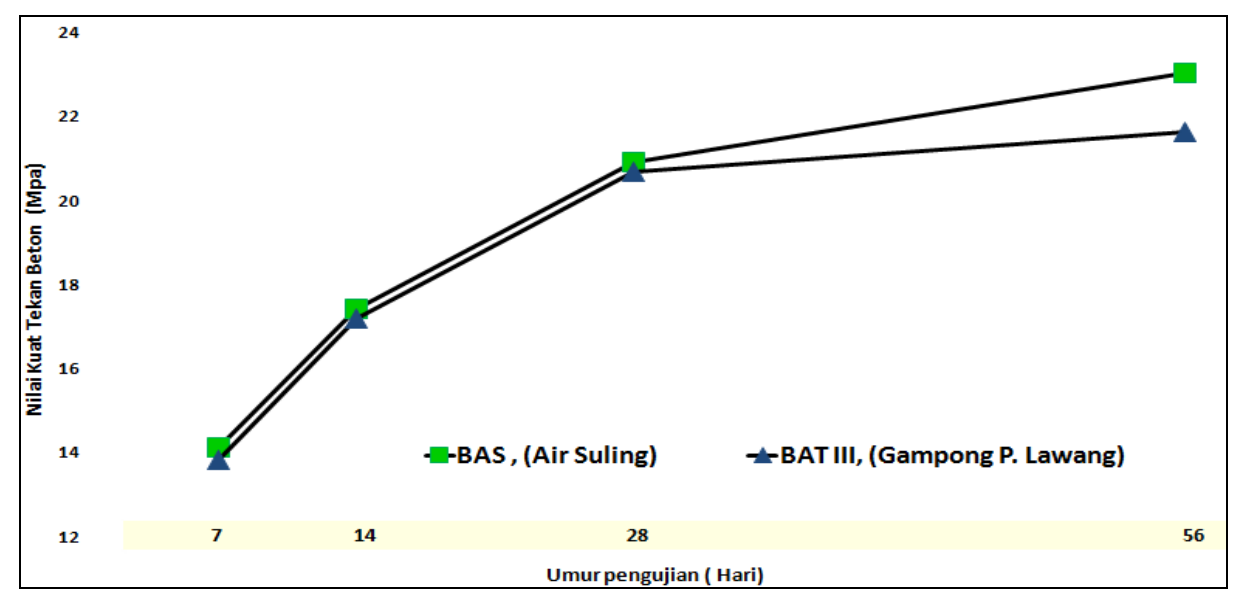

Gambar 3 Grafik hubungan nilai kuat tekan BAS dan BAT III VS umur pengujian

Gambar 3 memperlihatkan perbandingan nilai kuat tekan benda uji yang dibuat menggunakan air suling (BAS) dan air tanah (BAT III). Dari Gambar 3 
terlihat bahwa nilai kuat tekan benda uji BAS lebih besar dari nilai kuat tekan benda uji BAT III pada setiap umur pengujian. Grafik nilai kuat tekan beton hingga umur pengujian 28 hari menunjukkan pola peningkatan yang serupa, dan pada umur pengujian 56 hari terlihat terjadi sedikit perubahan pola pada nilai kuat tekannya. Pada umur pengujian 56 hari terlihat nilai kuat tekan benda uji BAT III mengalami persentase penurunan sedikit lebih besar terhadap nilai kuat tekan benda uji BAS pada umur pengujian sebelumnya.

Dengan menghubungkan data hasil pemeriksaan komposisi kandungan kimia sampel air pada Tabel 4 dan hasil pengujian kuat tekan beton pada Gambar 3 ditemukan bahwa fenomena ini terjadi karena perbedaan kandungan komposisi kimia air yang digunakan sebagai sebagai air campuran beton. Sampel air tanah BAT III memiliki komposisi kandungan kimia $\left(\mathrm{Cl}, \mathrm{Na}\right.$ dan $\left.\mathrm{SO}_{4}\right)$ dengan jumlah yang lebih besar dari air suling (BAS) yang digunakan sebagai pembanding.

\section{Kesimpulan dan Saran}

\subsection{Kesimpulan}

Dari hasil penelitian yang telah dilakukan jelas diketahui bahwa klorida dan sodium merupakan komponen unsur kimia yang paling dominan terkandung dalam air tanah selain sulfat dan komponen unsur kimia lainnya. Kuat tekan beton yang menggunakan air tanah sebagai air campurannya memiliki nilai kuat tekan akhir yang lebih kecil dibandingkan beton yang menggunakan air suling. Kandungan klorida dan sodium dengan jumlah yang dominan dalam air tanah yang digunakan sebagai air campuran beton menyebabkan kuat tekan beton meningkat pada awal umur pengujian 7 dan 14 hari tetapi mengalami penurunan secara signifikan pada umur pengujian 28 dan 56 hari. Berdasarkan ASTM C 1602 M-04 dan hasil pengujian kuat tekan beton disimpulkan bahwa sampel air tanah dari Gampong Pulo Lawang (AT III) layak digunakan sebagai air campuran beton sedangkan sampel air tanah dari Gampong Paya (AT I) dan Gampong Teupok Teungoh (AT II) tidak layak digunakan sebagai air campuran beton.

\subsection{Saran}

Untuk membuat konstruksi baik bangunan pemerintah maupun bangunan pribadin atau swasta di Kabupaten Bireuen hendaknya memperhatikan penggunaan air sebagai campuran beton

\section{Daftar Kepustakaan}

Tjokrodimuljo, K., 2007, Teknologi Beton, Biro Penerbit Teknik Sipil Keluarga Mahasiswa Teknik Sipil dan Lingkungan, Universitas Gadjah Mada Yogyakarta.

R.D.I. Kurnia, Suhaimi, S. Huzni and S. Fonna., 2018, Corrosion Potential of Reinforced Steel in Reinforced Concrete in Kabupaten Bireuen: Analysis of Groundwater Content Used as a Concrete Mixture, IOP Conference Series, Materials Science and Engineering. Padang. 
Khan. H, Izhar.T, Mumtaz. N, Ahad. A, 2016, Effect of Saline Water in Mixing and Curing on Strength of Concrete, IJSART - Volume 2 Issue 5, ISSN : 2395-1052.

Saribas. I, Cakir. O, 2017, Short-term Effects of Sodium Sulfate and Sodium Chloride Solutions on The Strength and Durability Properties of Hardened Mortars, European Journal of Science and Technology Vol. 6, No. 10, pp. 38-47.

Luca Bertolini, Bernhard Elsener, Pietro Pedeferri, Rob Polder 2004 Corrosion of Steel in Concrete, Prevention, Diagnosis and Repair (Weinheim WILEYVCH Verlag GmbH \& Co. KgaA).

ASTM Standard,. 2004, Annual Book of American Society for Testing and Materials Standard, New York, USA.

ASTM Standard,. C-1602., 2004, Standard specification for mixing water used in the production of hydraulic cement concret. New York, USA. 